\title{
Cor, gênero e classe: dinâmicas da discriminação entre jovens de grupos populares cariocas
}

\author{
Simone Monteiro** \\ Fátima Cecchetto***
}

\begin{abstract}
Resumo
Este trabalho discute as dinâmicas de discriminação entre moças e rapazes das camadas populares do Rio de Janeiro, considerando o papel que as hierarquias de cor/raça, gênero e classe social desempenham na configuração das práticas sociais. A análise tem por base entrevistas em profundidade com 42 jovens, de 18 a 24 anos. As situações de discriminação são referidas com maior frequência pelos rapazes. Entre os homens tais experiências estão associadas principalmente aos espaços públicos e ao mercado de trabalho, enquanto entre as mulheres a discriminação está mais vinculada aos espaços privados e ao local de moradia. Os dados estimulam uma discussão sobre a heterogeneidade das experiências de discriminação, na qual a cor/raça está associada às condições sociais e às relações de gênero.
\end{abstract}

Palavras-chave: Cor/Raça, Gênero, Discriminação, Juventude.

\footnotetext{
* Recebido para publicação em janeiro de 2008, aceito em junho de 2008.

** Pesquisadora do Laboratório de Educação em Ambiente e Saúde do Instituto Oswaldo Cruz, Fiocruz, Rio de Janeiro. msimone@ioc.fiocruz.br

**** Pesquisadora do Laboratório de Educação em Ambiente e Saúde do Instituto Oswaldo Cruz, Fiocruz, Rio de Janeiro. face@ioc.fiocruz.br
}

cadernos pagu (32), janeiro-junho de 2009:301-329. 
Cor, gênero e classe

Color, Gender and Social Class:

Dynamics of Discrimination of Lower Income Youth from Rio de Janeiro

\begin{abstract}
This work discuss the dynamics of discrimination of lower income male and female youths from Rio de Janeiro, considering the impact of the color/race, gender and social class hierarchies in the configurations of social practices. The analysis is based on in-depth interviews of 42 young people from 18 to 24 years of age. Situations of discrimination are much more referred to by men. The public spaces and the labor market are cited mainly by the boys. In the girls' view the discrimination is more associated to the place of residence and the private sphere. These data stimulate an analysis about the heterogeneity of the experiences of discrimination, where color/race is associated to social condition and gender relations.
\end{abstract}

Key Words: Color/Race, Gender, Discrimination, Youth. 
Este trabalho analisa as experiências de discriminação relatadas por um grupo de jovens das camadas populares, habitantes da cidade do Rio de Janeiro, tendo por base o papel que as hierarquias sociais, sobretudo a cor/raça, a condição de gênero e a classe social desempenham nas práticas sociais. $\mathrm{O}$ estudo integra uma pesquisa mais ampla ${ }^{1}$ que analisa, de forma comparativa, a trajetória de vida de jovens com e sem experiência em projetos sociais, no Rio de Janeiro. Dos 42 entrevistados, 24 tinham participado de projetos sociais e 18 não tinham tido esta experiência, mas ambos apresentavam semelhanças em relação a sexo, idade, inserção social e local de moradia. A comparação dos dados de um grupo com características etárias e sócio-econômicas semelhantes teve o propósito de analisar tendências relacionadas à influência de experiências sociais nas trajetórias de vida desses jovens. Foram também realizadas entrevistas com os educadores dos projetos e observação direta das atividades. Os projetos selecionados tinham em comum os objetivos gerais voltados para a promoção da cidadania $e$ a profissionalização de grupos de baixo poder aquisitivo, com prioridade para a faixa 14 a 21 anos, sendo que alguns enfatizavam a qualificação no âmbito artístico $e$ cultural e outros a formação técnica. ${ }^{2}$

\footnotetext{
1 A pesquisa faz parte do projeto: "Sexualidade, gênero e população negra no Brasil e na Colômbia: avaliações qualitativas", apoiado pela Fundação Ford.

2 Diante do grande número de projetos sociais dirigidos para jovens na cidade do Rio de Janeiro, foram adotados alguns critérios na escolha: 1) acesso mais seguro, por meio de contatos prévios, considerando os riscos decorrentes dos conflitos armados nas favelas cariocas; 2) incorporação de projetos desenvolvidos dentro de comunidades de baixa renda e fora das mesmas, como aqueles voltados para populações em situação de rua; 3) inclusão de pelo menos um projeto que já tivesse sido avaliado como bem sucedido no levantamento feito pela UNESCO (Castro et alii, 2001); 4) incorporação de projetos sociais desenvolvidos na Fundação Oswaldo Cruz; 5) perspectiva de comparação com o estudo de Monteiro (2002) desenvolvido com jovens da favela de Vigário Geral. Foi acordado que os nomes dos projetos não seriam divulgados, mas os representantes das quatro organizações tiveram acesso aos resultados do estudo.
} 
Cor, gênero e classe

A análise da biografia dos rapazes e moças com e sem participação em projetos sociais revelou que os jovens com experiência nos projetos apresentavam mudanças em suas trajetórias de vida, quando comparados aos seus pares do mesmo círculo, expressas pelo aumento do padrão de vida e das possibilidades de inserção profissional, pelo estímulo à escolarização e ampliação das redes de sociabilidade. Outro achado do estudo diz respeito às evidências sobre o maior conhecimento dos integrantes dos projetos na área da saúde sexual e reprodutiva, em relação às DSTs/Aids, à percepção de risco individual e à valorização do uso da camisinha. Tais dados adquiriram significado ao se constatar um maior cuidado deste grupo com a saúde e o controle da reprodução, expressos pelo adiamento da maternidade/paternidade e pela maior preocupação com a criação dos filhos. Embora haja o reconhecimento de que as ações dos projetos sociais se limitam a um número restrito de jovens e não promovem mudanças nas estruturas fomentadoras das desigualdades sociais, os resultados da pesquisa até então sugerem que certas iniciativas voltadas para a população juvenil urbana podem ampliar a perspectiva de vida e do capital simbólico deste grupo social, frente a um cenário de crise sócioeconômica. $^{3}$

Tendo por base as 42 entrevistas, no presente trabalho analisamos as percepções desse grupo de jovens, de ambos os sexos, sobre as situações de discriminação ${ }^{4}$ sofridas na vida cotidiana, seus contextos, motivações e freqüência, bem como os sentimentos e as reações gerados diante do ocorrido. Foi também indagado se as chances no mercado de trabalho eram iguais

${ }^{3}$ Para uma análise sobre os resultados descritos, ver Monteiro \& Cecchetto (2006).

${ }^{4} \mathrm{Na}$ literatura sobre relações raciais consultada, por vezes, é referida uma distinção entre preconceito e discriminação. De modo simplificado, podemos dizer que analiticamente o preconceito $e$ o racismo seriam modos de ver certas pessoas ou grupos raciais/étnicos, enquanto a discriminação seria a manifestação concreta desse pensamento (Guimarães, 2004). 
segundo gênero (homens e mulheres), cor (preto, pardos $e$ brancos) e poder aquisitivo (pobres e ricos). $\mathrm{Na}$ análise será destacado o papel da cor/raça nessas experiências, a perspectiva comparativa de gênero $e$ as repercussões decorrentes da inserção ou não nos projetos sociais. A abordagem dos projetos acerca do tema das relações raciais na sociedade brasileira, segundo a visão dos seus profissionais de educação, também será considerada na discussão. ${ }^{5}$ Por meio dessa reflexão, temos o propósito de ampliar o debate acerca dessa temática no Brasil, haja vista a escassez de estudos qualitativos nesse campo conforme revela a breve discussão acerca da produção acadêmica nacional no campo das ciências sociais, apresentada a seguir.

\section{Discriminação racial à brasileira}

Uma parte importante dos trabalhos sobre discriminação racial no Brasil se concentra no entendimento dos efeitos da discriminação no âmbito estrutural, destacando seu impacto na perpetuação das desigualdades sociais. Esse foi o ponto de partida das pesquisas de Hasenbalg (1979) no final dos anos 1970. Os achados trouxeram à tona inúmeros obstáculos para a mobilidade social de indivíduos então categorizados como não brancos. ${ }^{6}$ Os

\footnotetext{
5 Em trabalho anterior (Cecchetto \& Monteiro, 2006) centramos a análise na visão dos jovens do sexo masculino, particularmente aqueles com experiência em projetos sociais. No presente trabalho, reunimos e comparamos os depoimentos femininos e masculinos, dos/das jovens com e sem participação institucional, acerca das experiências de discriminação. Foram também considerados os relatos dos educadores sobre a abordagem das relações raciais nas ações dos projetos. A reflexão proposta visa promover um aprofundamento das implicações das experiências sociais e de gênero na discussão das vivências de discriminação $e$ do preconceito racial do grupo de jovens do estudo, bem como discutir as implicações da participação institucional para a percepção das situações de discriminação.

6 Tendo em vista às variações das categorias usadas na classificação da cor/raça, neste trabalho os termos serão apresentados em itálico, ora referentes às obras citadas, ora às auto-classificações dos entrevistados.
} 
Cor, gênero e classe

dados censitários sobre a discriminação e o racismo, embora já preocupasse intelectuais e ativistas do movimento negro da época, indicaram a acentuada desigualdade racial, particularmente no mercado de trabalho e no sistema educacional. Tais análises, aprofundadas em conjunto com Nelson do Valle Silva, foram incorporadas com força ao idioma dos movimentos sociais vinculados à temática racial, reforçando a tese na qual o viés "racial" das desigualdades sociais no Brasil não se constituía apenas numa reprodução de desvantagens históricas (Fry, 2006).

O espaço alcançado pelos dados estatísticos acerca da discriminação e da desigualdade racial no país tem, desde então, orientado estudos de cientistas sociais sobre a desigualdade hierárquica entre brancos e negros (Guimarães, 2004). Pesquisas recentes assinalaram as barreiras experimentadas pelas pessoas com o fenótipo ou cor negra em relação ao acesso ao ensino público superior (Teixeira, 2003) e ao emprego em setores qualificados do mercado de trabalho (Araújo Guimarães, 2004; Lima, 1999), bem como ao exercício da igualdade de direitos na esfera da cidadania e da justiça penal (Adorno, 1996; Guimarães, 1996). Cabe ressaltar que no rastro analítico dos referidos estudos, o ativismo negro passou a considerar a persistência da desigualdade racial, não só como uma evidência do fracasso das políticas sociais, mas como o declínio de certas narrativas ideológicas que orientavam a pauta anti-racista na sociedade brasileira. De forma resumida, podemos dizer que nos anos 1970 a raça pouco se impunha como categoria analítica ou variável interveniente para tratar as desigualdades sociais. Estas eram compreendidas sob o prisma do conceito de classe, fundamentado nas teorias de modernização e na sociologia de estratificação social, de inspiração marxista. A metodologia empregada nesses estudos de base censitária, além de inaugurar um novo paradigma nos estudos das relações raciais, favoreceu o estabelecimento de uma nova configuração do racismo, o racismo estrutural, que passa a ser uma importante variável para explicar as desigualdades sociais (Grin, 2006). 
Nesse cenário o tema do racismo (ou do preconceito racial) ganha vulto, atraindo críticas severas ao chamado "tratamento culturalista" dado à "questão racial" brasileira por diversos intelectuais ao longo da história republicana. Tal perspectiva tem como eixo a reinvenção da "raça", expressa nas propostas de ações e políticas racializadas como meta para combater o racismo (Htun, 2004; Maio \& Monteiro, 2005). Segundo Fry (2006), o principal argumento crítico estava centrado na democracia racial, acusada de ser um mito (em sua acepção de ocultamento da realidade) e não em uma afirmação ritualizada de princípios considerados fundamentais à constituição da ordem social, no sentido antropológico do termo. Como afirma o autor,

(...) a democracia racial foi apontada não apenas como algo que mascara a dura realidade da discriminação $e$ desigualdades raciais, mas como causa principal dessas desigualdades raciais (Fry, 2006:183).

Frente à visibilidade e repercussão das críticas à denominada visão culturalista, pode-se dizer que, a despeito da afirmação quase unívoca da existência do racismo na sociedade brasileira pela população ${ }^{7}$ e estudiosos do tema, não há consenso quanto às formas de enfrentamento das desigualdades raciais. Tais diferenças têm sido objeto de intensas controvérsias em torno, principalmente, das políticas anti-racistas, instaurando clivagens não só nos meios acadêmicos, mas também na política contemporânea no Brasil e nos movimentos sociais. Segundo definição de Costa (2002:108), existiriam duas vertentes ou formas assumidas pelas proposições conceituais e políticas do anti-

7 Estudos sobre o preconceito e a discriminação racial entre os habitantes das grandes cidades do país apontam que a maior parte dos indivíduos reconhece a existência do racismo na sociedade brasileira. Todavia, grande parte das pessoas afirma não ter atitudes racistas, revelando um descompasso entre a visão dos indivíduos sobre o tema e a auto-percepção do preconceito (Turra e Venturi, 1995). 
Cor, gênero e classe

racismo na atualidade, quais sejam: as correntes "igualitarista" $e$ "integracionista". A diferença central entre ambas consistiria no peso da raça ou da racialização no processo de implementação de políticas de ação afirmativa para reverter as iniquidades sociais experimentadas pelos indivíduos socialmente identificados como negros ou afro-descendentes. Assim, para a corrente integracionista, a particularidade cultural da idéia de mistura e do continuum de cores - traduzida pela convivência e integração de diferentes grupos de cor - tem um "valor negociável" e deve ser preservada como um conjunto de práticas e valores internalizados como legítimos.

Para a corrente igualitarista, a ênfase recai na racialização das identidades sociais, com base na polarização entre brancos e negros. Dessa forma, contesta os critérios universalistas na distribuição de direitos e prioriza a produção de uma "igualdade efetiva de oportunidades" para a mobilidade social da população negra. Essa perspectiva tem se apoiado em dados de investigações sociológicas, de recorte quantitativo acerca da variável raça ou cor, como matriz explicativa das diferenças sociais estruturais no Brasil. ${ }^{8}$ Nesse cenário, ganha relevância as investigações qualitativas sobre o tema, capazes de levar em conta os valores e os significados das relações raciais em contextos culturais específicos, desatrelados da afirmação de identidades políticas. Esse enfoque, entendido como complementar aos estudos quantitativos, pode lançar luzes sobre as particularidades das relações raciais no cenário nacional.

\footnotetext{
8 A importância da produção de dados estatísticos acerca das piores condições dos negros em relação aos brancos para a consolidação de políticas raciais na área da saúde pública foi referida por Maio \& Monteiro (2005). A reflexão dos autores se apóia nos argumentos de Pinto e Souza (2002) e Pinto (2005) acerca do papel da produção da informação na constituição e afirmação da "identidade negra" e do uso das análises estatísticas enquanto expressão da "realidade" social.
} 
Fátima Cecchetto e Simone Monteiro

\section{A discriminação racial em contextos de sociabilidade distintos}

Dentre os trabalhos de sociólogos sobre a dimensão da cor nas diferentes sociedades, os clássicos estudos de Nogueira (1998) foram fundamentais para a compreensão da natureza e dos processos discriminatórios articulados à estruturação da cor/raça no contexto nacional. Tendo por base uma análise comparativa entre os Estados Unidos e o Brasil, o autor distingue dois tipos de preconceito associados à cor/raça, diretamente ligados aos contextos daqueles países. Enquanto na sociedade norteamericana, o preconceito está relacionado à ascendência ou a origem, no Brasil seriam as marcas fenotípicas - como o tom da pele, tipo de cabelo, formato dos lábios e do nariz, sobretudo quando elas se aproximam mais das marcas ou tons de pele negra ou preta -, que mobilizariam o preconceito. Quer dizer, a experiência decorrente do "problema da cor" na sociedade nacional varia segundo a maior ou menor presença de marcas fenotípicas e de que modo elas são contrabalançadas com outros aspectos como instrução, polidez, elegância, entre outros.

A constante sobreposição e a estreita correlação entre categorizações de cor e classe, registradas nas observações de Nogueira, foram interpretadas por Fry $(2005,1991)$ e Maggie (1996) como especificidades das relações raciais brasileiras, sustentadas por princípios classificatórios flexíveis na atribuição da cor e nas práticas discriminatórias correntes. Dito de outra maneira, para os antropólogos mencionados a singularidade cultural brasileira é um traço positivo e representa uma forma de convivência definida pela mistura de cor/raça e de alteridades nos planos simbólico, econômico e político. Com base nessa argumentação, tem sido possível afirmar que a discriminação racial também pode ser compreendida como um procedimento situacional que inclui combinações entre as variáveis atribuídas à pessoa (os traços fisionômicos) e as adquiridas (ex. classe; convenções de gênero e outros marcadores sociais). 
Cor, gênero e classe

Os estudos mais recentes, sobretudo os de recorte etnográfico, ressaltam algumas dinâmicas específicas da discriminação na esfera do lazer. O trabalho de Sansone (2004) sobre os contatos inter-raciais no estado da Bahia mostrou a existência de uma gradação hierárquica entre áreas ou domínios onde a cor negra pode ser um fator de prestígio ou um empecilho nas relações sociais. Nessa lógica, o mercado de trabalho seria uma área considerada desfavorável ou dura, ocorrendo nela o máximo de discriminação para as pessoas negras, enquanto em alguns ambientes de lazer (e de festas populares), incluindo a Igreja Católica, denominadas de mole, haveria o mínimo de discriminação.

Maurício (1998), implicitamente trilhando os caminhos abertos por Nogueira, em interessante etnografia no transporte público do Rio de Janeiro, discute as "mediações subjetivas" feitas pelos usuários. Ao observar os padrões que orientavam as escolhas dos passageiros, segundo gênero e cor do possível companheiro de viagem, o autor identificou uma espécie de escala de preferência. Os passageiros de pele mais clara (brancos; morenos), de ambos os sexos, escolhiam primeiro os lugares ao lado das mulheres brancas e, em segundo, os das mulheres de pele mais escura (pretas; negras). Os assentos vazios contíguos aos homens eram evitados, sendo que os lugares ao lado dos homens de pele mais escura eram a última opção. Segundo o estudo, essa seletividade estava conectada com dois pressupostos combinados. O primeiro, implícito no senso comum e policial carioca, associa a cor escura a um indício de criminalidade e ameaça, sobretudo, rapazes pretos/negros que circulam em lugares públicos. ${ }^{9} \mathrm{O}$ outro, de caráter mais explícito, refere-se ao medo de assalto pela população carioca nos transportes coletivos, domínio em que a

9 Tal associação é recorrentemente atualizada pelas imagens divulgadas na mídia impressa e televisiva sobre os chamados arrastões, em que um grupo de jovens, majoritariamente de pele mais escura, ameaça a população em locais públicos de centros urbanos como Rio de Janeiro e São Paulo. 
probabilidade de se sofrer várias violências é grande, dada à ausência de medidas de segurança pública adequadas.

Farias (2003), em pesquisa sobre as relações raciais nas praias cariocas, caracterizou uma dimensão importante das dinâmicas locais de classificação da cor interligada à discriminação racial: a noção de território (em sua acepção simbólica relacionada a um ethos específico ou moralidade). As praias localizadas na zona sul da cidade constituem-se como um espaço ou área moral, onde seus habitués operam uma classificação social da pessoa ou dos grupos, tomando por base o local de moradia, e não a cor. Assim, territorialidade serve como um marcador explícito e ajuda a subsumir a discriminação racial a uma categorização de posição social ou status, indicando, mais uma vez, a combinação de variáveis sociais na dinâmica da discriminação.

Desse modo, em que pesem as evidências sobre as desigualdades raciais, não se pode ignorar os espaços sociais $e$ as dinâmicas locais no entendimento da lógica da discriminação. Aliado a este desafio, que impõe uma discussão sobre quais as estratégias metodológicas mais adequadas para abordar o tema, nos parece importante o entendimento das experiências segundo o gênero; isto é, o modo como homens e mulheres interpretam as situações de discriminação nos mais diversos âmbitos da vida social $^{10}$ e os significados atribuídos a essas experiências, tanto no plano da subjetividade quanto no plano sócio-político. Nesse sentido, tomamos a condição de gênero como um princípio classificatório que mantém uma estreita correlação com os tipos de ações discriminatórias vividas pelos indivíduos e grupos nas sociedades contemporâneas (Stolcke, 1991).

${ }^{10} \mathrm{Na}$ esfera das relações afetivo-sexuais, Moutinho (2004) identificou no erotismo um componente fundamental para a compreensão da lógica que preside certas interações entre casais heterocrômicos em que a etiqueta é não falar explicitamente de cor. A adoção de tal regra por esses casais, ajuda a entender alguns dilemas das relações raciais brasileiras para lidar com as sutilezas do preconceito racial e da discriminação. 
Cor, gênero e classe

Nessa lógica, as explicações para as experiências concretas de discriminação interligadas às categorias cor/raça e gênero têm por base as reflexões acerca da desnaturalização $e$ contextualização das diferenças. Tal visão segue a tradição da abordagem antropológica, de base universalista, que recusa correlações fixas entre características físicas e atributos morais $e$ intelectuais (Schwarcz, 1996). Entretanto, reconhece que as crenças em atributos distintivos ligados às "raças" persistem até hoje como mitos sociais e como base para a construção de diferenças entre as pessoas, promovidas pelos saberes ocidentais desde o século XIX (Fry, 2005).

É importante ressaltar que o uso do termo etnicidade (popularizado nas ciências sociais no entre-guerras e, muitas vezes reificado no plano cultural) não registrou o mesmo avanço, quando comparado às conquistas da categoria gênero como uma elaboração cultural (Stolcke, 1991; Heilborn, 1993). Isso significa dizer que, apesar dos estudos contemporâneos no campo da genética molecular e do sequenciamento do genoma humano afirmarem que o conceito de raças humanas é inconsistente do ponto de vista biológico (Penna, 2005), raça ainda é um poderoso construto social, histórico e político. Quer dizer, é um conceito que contagia o tecido social e ganha concretude como marcador social da diferença. É preciso, portanto, considerar os diversos arranjos culturais através dos quais as formas específicas de discriminação se manifestam no plano da interação social. Nessa direção, a análise das experiências de discriminação de um grupo de rapazes e moças das camadas populares, tratadas a seguir, visa identificar de que modo as categorias cor/raça, gênero e inserção social estão inter-relacionadas, mas não necessariamente redutíveis umas às outras, nas relações sociais que se estabelecem na vida cotidiana.

\section{Experiências de discriminação segundo o recorte de gênero}

A análise sobre os significados atribuídos às experiências de discriminação segundo um grupo de jovens foi orientada pela 
perspectiva comparativa de gênero, visando identificar as aproximações e diferenças entre as falas masculinas e femininas. Igualmente, procuramos examinar se aqueles/as com inserção em projetos sociais apresentavam falas distintas daqueles/as sem experiência nos referidos projetos. De modo a organizar os achados, agrupamos a discussão em quatro matrizes: breve perfil do grupo pesquisado; percepções sobre os motivos da discriminação; contextos, tipos de discriminações e reações dos jovens; abordagem dos projetos sociais segundo a visão de seus profissionais da área de educação.

\section{Breve perfil do grupo}

Dos 42 entrevistados, 24 tinham participado de projetos sociais e 18 não passaram por essa experiência institucional. Todos freqüentaram a escolarização formal, mas apenas metade estava estudando. Comparativamente, os jovens sem inserção em projetos sociais revelaram menor escolaridade, apesar das diferenças não serem expressivas.

No que diz respeito às suas famílias de origem, notou-se que grande parte era da região Sudeste. Os/as jovens eram moradores de favelas e/ou bairros populares. A maioria vivia nesses locais desde seu nascimento, apontando para a permanência desse grupo com suas famílias de origem. Em relação à conjugalidade, apenas dez afirmaram manter uma união estável; os demais informaram que estavam solteiros ou namorando.

Do total de entrevistados, cerca da metade informou que estava trabalhando. Desses, a maior parte havia participado dos projetos sociais e estava exercendo atividades vinculadas ao setor cultural (monitores de projetos, percussionista, ator) ou ocupados no setor de serviços (farmácias, supermercados, confecções). Comparativamente, os jovens sem experiência em projetos estavam mais representados no setor informal do mercado de trabalho (ambulante, catador de lixo, biscateiro) ou desempregados, principalmente as mulheres. 
Cor, gênero e classe

Segundo os dados relativos à auto-classificação da cor/raça - obtidos pela pergunta Qual a sua cor ou raça? - 18 se declararam como negros, 8 como pardos, 6 como morenos, 5 como pretos/pretinha e 4 como brancos. Uma foi ambivalente (morena-preta) e outro não deu resposta.

Não foi surpreendente encontrar uma minoria de brancos nesse universo, haja vista que as estatísticas nacionais atestam a maior concentração de pretos e pardos nos segmentos populacionais de menor poder aquisitivo. Chama atenção a maior frequência do termo negro entre os jovens que integraram os projetos e o uso da categoria preto apenas por aqueles sem a referida inserção. Isso não significa afirmar que o modelo bipolar de classificação tenha sido adotado como forma corrente pelo grupo, uma vez que permanece o uso da categoria pardo $e$ moreno. Tal fato, possivelmente, se deve à mudança do sinal de valor do termo negro em alguns espaços sociais, aonde a designação racial de uma pessoa como negro/a vem perdendo uma conotação negativa em função da identificação, sobretudo das gerações mais jovens, com os circuitos transnacionais de valorização de símbolos da chamada cultura negra (Sansone, 2004:78-89). A conotação positiva do termo negro pode também ser atribuída à visibilidade adquirida pelo tema das relações raciais no cenário nacional, expressa, por exemplo, pelo debate público em torno das políticas recentes de recorte racial.

\section{Percepções sobre os motivos da discriminação}

Do total dos 42 jovens entrevistados, 30 declararam ter vivido alguma experiência de discriminação, sendo 20 homens e 10 mulheres (ver quadro em Anexo). Nota-se, portanto, que a maioria que negou ter sofrido discriminação pertence ao universo feminino, o que sugere implicações associadas ao gênero. Vale notar que foram identificados pontos em comum nas visões $e$ vivências descritas pelos rapazes e moças, mas há algumas distinções de gênero vinculadas aos contextos e motivações, 
conforme veremos a seguir. A comparação entre os relatos dos jovens com e sem inserção nos projetos sociais, embora não tenha apontado para variações expressivas, indicou diferenças nas reações frente às situações de discriminações ocorridas.

A análise anterior dos depoimentos sobre as motivações percebidas no universo masculino (ver nota 5), revelou que entre os homens prevalece a cor, seguida do local de moradia e do que foi designado na análise como aparência, definida nas falas como "modo de vestir", "condição social" e "deficiência física". Desses rapazes que atribuíram a discriminação por cor, metade também mencionou a aparência e parte citou o local de moradia. Por exemplo, um dos jovens auto-classificado como negro denominou de discriminação por cor a atitude de um segurança que o impediu de entrar numa agência bancária, mas não importunou um rapaz branco. Esse mesmo depoente citou a discriminação por aparência ao afirmar que "muitos acham que assaltante são aqueles mal vestidos". Um outro rapaz pardo registrou:

Quando eu vou procurar emprego eu botava o meu endereço no currículo: "A pode aguardar". Até hoje estou aguardando (...) Então quer dizer já começou a discriminação dali. Eu li uma reportagem que pessoas jovens que moram no Morro do Alemão (...), Cidade de Deus, não conseguem emprego por morar ali. Será que só pessoas barra ali dentro do Morro do Alemão? Tem pessoas boas, Só que a sociedade não vê o outro lado.

Tais dados sugerem que para os homens auto-declarados negros e pretos o baixo status social (expresso pelo modo de vestir e pelo local de moradia) tem peso tão expressivo quanto a cor nas situações de discriminação. Isso pode ser debitado ao padrão classificatório brasileiro, ressaltado por Nogueira (1998). Quer dizer, nas explicações sobre a discriminação no Brasil a cor não é o critério determinante, uma vez que a postura corporal, "o jeito", o vestuário e o contexto são percebidos como elementos igualmente relevantes. 
Cor, gênero e classe

De modo contrastante, nas falas femininas a forma de discriminação mais citada refere-se ao local de moradia. Segundo os relatos das moças, o tipo de discriminação percebido é ocasionado por acusações ligadas ao local de moradia, que remetem ao pertencimento social $e$ às conotações negativas da favela, associada a eventos violentos, conforme ilustra o relato:

[Por que você foi discriminada?] Ah, por morar aqui em Vigário, isso acontece muito, até em nível de emprego. Se falar que mora em Vigário Geral, não tem... Acho que dá certo medo, de falar que eu moro em Vigário Geral. Não digo que moro de jeito nenhum. As pessoas lembram da chacina. [o assassinato de 21 pessoas pelo polícia em 1993].

Nesse ponto, há um componente importante na compreensão dessa variação entre rapazes e moças. Trata-se da dimensão de gênero, que interligada às condições materiais de existência parece agir no sentido de tornar mais invisível a discriminação racial sofrida pelas mulheres, conforme argumenta Crenshaw (2002). Os poucos depoimentos feitos por elas relativos à aparência não mencionam a cor de modo explícito, como os rapazes. Isso combina com o expressivo número de mulheres que não mencionaram experiências ligadas a preconceitos $e$ discriminações.

Nessa direção, vale destacar as diferenças entre os depoimentos femininos e masculinos acerca da percepção das desigualdades nas oportunidades no mercado de trabalho em função de gênero, cor e poder aquisitivo. Enquanto alguns rapazes percebem a diminuição da assimetria de gênero, pela conquista das mulheres no âmbito da profissionalização, nos relatos femininos verifica-se uma maior percepção da assimetria de gênero na produção da desigualdade, caracterizada pela identificação de maior favorecimento para os homens. Em termos da cor, embora a maioria reconheça a presença de desigualdades 
entre pardos, pretos e brancos, tal percepção é menor entre as mulheres, reforçando a maior invisibilidade da cor para o grupo feminino. No que diz respeito à desigualdade entre ricos e pobres, predomina entre ambos os sexos a ênfase na falta de escolaridade dos pobres na determinação das oportunidades.

\section{Contextos, tipos de discriminação e reações}

Em relação aos contextos da discriminação, os depoimentos masculinos e femininos apresentam algumas aproximações, mas guardam especificidades. Ambos indicaram os espaços públicos, como shoppings centers, agências bancárias, ruas e restaurantes. Nesses locais o preconceito se traduz pelo distanciamento dos transeuntes, descaso no atendimento, perseguição e violência dos seguranças dos estabelecimentos comerciais, assim como da própria polícia, principalmente para os homens.

O mercado de trabalho também foi identificado como uma área desfavorável tanto para a cor quanto para o local de moradia, segundo rapazes e moças, reforçando os achados da literatura citados anteriormente. Nota-se, todavia, uma diferença associada ao gênero. Para as mulheres, é no âmbito das relações estabelecidas no trabalho que elas percebem a discriminação por parte de pessoas conhecidas que ocupam postos hierarquicamente superiores, em função do endereço residencial. Ilustra esse achado o depoimento de uma moça, auto-denominada parda e com experiência em projetos sociais, que se via constantemente confrontada com a noção de que seu local de moradia representava uma ameaça:

[Quais situações você percebeu que viveu alguma discriminação?] Ah, as pessoas aqui de dentro, quando souberam que tinham pessoas da favela, como eles dizem mesmo, eles começaram a ficar receosos. Do tipo, poderia sumir sua carteira, sua bolsa. ...a gente sofreu uma barra aqui dentro, porque as pessoas te olhavam como se fosse uma pessoa qualquer. Pessoas mesmo que pegam ônibus. 
Cor, gênero e classe

$\mathrm{Na}$ verdade, pessoas que humilham outras pessoas..., pessoas que são iguais a você, mas se sentem superior quando estão em determinados locais. Então a gente sofreu uma barra.

A discriminação por cor foi referida no ambiente da família, como indica outro depoimento de uma garota, auto-definida como negra e integrante de projeto social, referente à fala racista no convívio familiar, curiosamente percebida como algo "inconsciente", embora provoque reações de irritação:

Olha, ultimamente eu tenho me sentindo tão discriminada aqui em casa. Já viu a cara do meu esposo? Ele é brancão com olhos azuis. Aí toda vez tem que surgir o negócio de cor. [como é isso?] Eu já falei [reproduzindo um diálogo com o marido]: "todo mundo pode me discriminar, menos você. [por que isso?] Porque tem uma crença boba, que a mulher negra é quente, é boa de cama, mas não é boa... é assim, pode falar que não, mas é: ela não serve para ser esposa, mas serve para esquentar os pés, que merda é essa? Aí teve um dia desses que a gente estava numa festa e passou uma criança correndo igual uma espoleta, aí eu falei: olha que coisa linda, nosso neném vai ser assim. [marido]: "Você está maluca, claro que nosso filho não vai ser assim, nosso filho vai ser preto" eu falei: quem é que está falando da cor? Estou falando que vai ser saudável, brincalhão, vai correr, vai ser um espoleta, porque se puxar a mãe, vai ser. Mas você sente que é inconsciente, mas é uma discriminação. (...) Igual minhas colegas: tomara que seu filho nasça de cabelo liso e olho claro, não é? (...) Meu cabelo não é ruim porque ele não rouba, não cheira, não fuma, não mata, ele é crespo. O cabelo da raça dele é assim, da minha raça é assim. As pessoas fazem discriminação sem sentir. ...Em festa. (...) Se eu como muito: que crioula mal-educada, mas se você come muito, ninguém fala nada. 
Podemos dizer que entre as mulheres pesquisadas, a situação de discriminação recorrente foi relacionada a comentários preconceituosos ou estereótipos lançados sobre sua origem social em locais públicos (mais circunscritos ao ambiente profissional) $e$ no espaço privado do lar, no universo da "casa" e não da "rua" (DaMatta, 1985). Notamos que as queixas versavam sobre formas discriminatórias que interferiam principalmente no convívio social e familiar, contrastando com o peso do universo público (da "rua"), identificado pelos rapazes.

No universo masculino, o tipo mais comum foi aquele relacionado ao impedimento ou constrangimento sofrido em estabelecimentos comerciais e/ou bancários, e em vias públicas, por seguranças ou policiais, com o uso da agressão verbal e física, independente da vinculação institucional com os projetos sociais. Tal achado converge com a produção acadêmica sobre o tipo de discriminação que mais afeta os homens, principalmente de baixo status social. Essa forma discriminatória encontra-se respaldada em uma idéia racista bastante invocada no senso comum, incluindo a polícia, de que a cor preta ou negra, combinada a outros atributos, é um bom indicador da criminalidade. Em geral, os considerados suspeitos por sua aparência (indicador de classe ou posição social) ou cor (traço fenotípico) sofrem abuso de poder ou são tratados com violência física como foi o caso de dois entrevistados, agredidos por seguranças privados. A conduta de policiais orientada por pressupostos racistas foi confirmada no trabalho de Ramos \& Musumeci (2005). As autoras descrevem como se dá a construção do "elemento suspeito de cor padrão", isto é, homem "de cor" e de classe baixa, alvo prioritário de revistas e prisões para averiguações de rotina.

Frente a esses achados interpretamos que as diferenças encontradas nos depoimentos masculinos e femininos ocorrem em função das situações de discriminação experimentadas por cada universo. Enquanto os homens são, em geral, vítimas e também protagonistas de formas violentas de discriminação, as mulheres tendem a ser alvo preferencial de formas verbais ou mais veladas, 
Cor, gênero e classe

como às direcionadas à aparência $e$ ao corpo. Isso quer dizer que o universo feminino é mais suscetível que o masculino a comentários jocosos ou acusatórios sobre a sua aparência física (feiúra; cabelo ruim; vestuário inadequado) e seus os atributos sexuais (maior vigor e liberação sexual).

A configuração sobre as diferenças de gênero na vivência $e$ percepção da discriminação ganha maior destaque no caso da percepção da discriminação "racial", tendo em vista que existe o entendimento no cotidiano de que as falas ou ofensas verbais não constituem racismo. Segundo Guimarães (2004), tal pensamento encontra bastante aceitação entre os operadores da justiça, incluindo policiais que registram as queixas nas delegacias, $e$ "decidem" em quais artigos da lei serão feitos os enquadramentos. Essas práticas, muitas vezes, resultam em controvertidas classificações que minimizam a discriminação, considerando-as como crimes contra a honra, sobretudo quando a vítima é mulher. Para o autor, isso resulta dos padrões brasileiros ligados à percepção do racismo somente como segregação. Em geral, as pessoas entendem a discriminação de que são vítimas, cotidianamente, como decorrente de seu status social e não de sua "cor".

No que diz respeito às reações geradas pelas experiências de discriminação foram encontradas semelhanças entre os gêneros nas atitudes dos/das jovens. Tanto para rapazes quanto para moças prevalece a interiorização de sentimentos negativos, expressos pela sensação de humilhação, tristeza, constrangimento e mal-estar. Alguns afirmaram que reagiram com ironia ou indiferença $e$ apenas um rapaz mencionou a possibilidade de recorrer à justiça ou a organizações da sociedade civil que prestam orientação e assistência na área do direito. Podemos supor que a não procura por órgãos responsáveis pela garantia dos direitos dos cidadãos resulta da tendência da justiça em enquadrar a maioria dos casos de racismo como injúria, conforme argumenta Guimarães acima. 
Por fim, é interessante salientar que, diferentemente das situações de discriminação em que a cor foi explicitamente evocada, as manifestações de preconceito ligadas ao local de moradia suscitaram reações de positivação do lugar entre os rapazes e as moças. Tal achado converte com o valor do espaço local, compreendido pela noção de território. Apesar do crescimento alarmante das mortes violentas nas décadas de 1990, devido às disputas territoriais pelo controle do negócio das drogas nas favelas e bairros pobres cariocas, o território em sua acepção do "sentir-se em casa" é celebrado entre os habitantes das favelas da cidade do Rio de Janeiro, sobretudo pelos mais jovens. Ele se configura como um lócus de sociabilidade juvenil pela centralidade adquirida pelo lazer na definição de novas identidades no contexto urbano. Isso significa que a noção de território vem se colocando como uma importante variável junto com cor, geração e gênero nos estudos sobre a juventude (Farias, 2000; Cecchetto, 2004).

\section{Abordagem dos projetos sociais}

Com o objetivo de aprofundar a análise acerca da repercussão dos projetos sociais na trajetória daqueles jovens que tiveram experiência em projetos sociais, foram entrevistados noves profissionais que tinham atuado em atividades educativas nos referidos projetos. Um dos focos da entrevista foi centrado na descrição da abordagem do tema das relações raciais nas ações dos projetos. Os dados das entrevistas, somados a análise dos documentos e publicações produzidas pelos projetos, indicam que, de modo geral, o trabalho institucional era centrado na profissionalização e no exercício da cidadania de jovens das camadas populares, não havendo ênfase na diferenciação de grupos "raciais". Do total dos profissionais entrevistados, apenas um explicitou a valorização de "códigos e símbolos da cultura negra" e dos estilos musicais (samba, rap, funk) no desenvolvimento do trabalho. Nessa direção, ele afirmou que 
Cor, gênero e classe

buscava resgatar aspectos históricos relacionados à exclusão social dos negros e o papel de lideranças negras. A valorização do local de moradia, no caso, as favelas, associada ao combate ao preconceito também foi ressaltada por esse educador. As associações entre o preconceito de cor e de classe social foram mencionadas por profissionais, de outro projeto, no sentido de ilustrar a percepção da maior vulnerabilidade social dos jovens pretos/negros e pobres e com baixa escolarização.

Nota-se que a classe social tende a adquirir uma maior centralidade na percepção da desigualdade social entre os profissionais dos projetos sociais, não sendo identificada uma abordagem focada na afirmação da identidade e/ou consciência racial. Prevalecem articulações que visam fortalecer uma rede de apoio local, por meio do estabelecimento de parcerias voltadas, sobretudo, para ampliação das possibilidades de serviços assistenciais aos jovens e suas famílias (atendimento social, psicológico) e serviços profissionalizantes (cursos).

Em termos da repercussão dos projetos sociais, chama a atenção que os dois rapazes que reagiram a situações de discriminação (um deles procurou uma delegacia para fazer queixa) foram integrantes desses projetos. Entre as mulheres participantes de projetos também houve reações diante de atitudes desfavoráveis ou de um racismo implícito no exercício profissional. Entretanto, boa parte das moças sem experiência institucional não mencionou vivências de discriminação; nesse universo predomina a fala sobre a maior dificuldade de acesso ao mercado de trabalho. Ou seja, a percepção da experiência de discriminação foi mais recorrente entre os homens e entre os/as jovens que integraram os projetos sociais analisados.

Podemos então supor que a experiência institucional contribui para a conformação das visões e comportamentos desses $e$ dessas jovens em relação às situações de discriminação, no sentido de favorecer um reconhecimento de que seus direitos enquanto cidadãos estão sendo violados em função das diferenças de classe, cor/raça e/ou gênero. Tais mudanças devem ser 
compreendidas a partir do estudo comparativo, referido na introdução, sobre as trajetórias dos/das jovens com e sem participação nos projetos sociais pesquisados. Conforme os achados, aqueles/aquelas jovens com experiência institucional revelaram melhor inserção no mercado de trabalho, melhoria na escolaridade, expansão do círculo de relações e incorporação, mesmo que parcial, de uma perspectiva mais igualitária das relações de gênero, quando comparados aos sem vivência institucional. As diferenças de gênero foram indicadas pela maior vulnerabilidade social do grupo feminino entre os sem participação em projetos sociais.

\section{Reflexões finais}

A interpretação dos relatos dos rapazes e das moças indica que as situações de discriminação são apreendidas de forma distinta segundo o gênero. A experiência em projetos sociais também repercute, particularmente em termos das reações frente às situações de discriminação percebidas. A classe social ainda é um recurso para se falar de cor/raça $e$ as desigualdades sociais nem sempre são vistas como desigualdades raciais pelo grupo pesquisado.

Em relação aos rapazes, a observação a ser feita refere-se à importância do espaço público, a "rua", como o lócus principal da discriminação a eles dirigida, sendo recorrente o abuso do poder policial, incluindo o uso da força física. Eles se confrontam com situações em que o preconceito de cor/raça é articulado à pobreza urbana. Nesse particular, cabem os argumentos de Zaluar (2004) sobre o impacto da desigualdade social para as camadas populares cariocas. As pesquisas da autora em favelas da cidade, desde os anos 1980, identificaram a sobre-representação de jovens, principalmente pobres e negros como as maiores vítimas de homicídios nos circuitos da violência urbana. A integração perversa entre pobreza e redes de crime-negócio de drogas $e$ armas no Rio de Janeiro atingiu em particular os rapazes. No 
Cor, gênero e classe

limite, a alta mortalidade masculina entre jovens pobres revela em parte a discriminação à brasileira, ou seja, uma conduta que legitima a cor e a classe como critérios que tornam a pessoa, em geral do sexo masculino, um suspeito ou criminoso. A ausência de políticas sociais de combate à pobreza e de mudanças na esfera da segurança pública vêm contribuindo para a superposição de dois status pouco prestigiados na sociedade brasileira: a cor preta/negra e a pobreza.

No que diz respeito às percepções e vivências da discriminação no universo feminino nos chamou atenção a ressignificação das experiências no espaço público. Diferentemente dos homens, o tipo de discriminação que mais afeta e mobiliza as mulheres é aquela que parte de pessoas conhecidas ou alguém com quem se convive socialmente em ambiente público e até privado. Trata-se de uma forma de discriminação da "casa" e não da "rua" para usar a classificação dicotômica de Da Matta (1985). Ou seja, para as mulheres é mais recorrente que os ofensores sejam de seu círculo de relações interpessoais, ao contrário dos homens, normalmente atingidos por discriminações feitas por estranhos ou por indivíduos investidos de autoridade com o objetivo de impedir sua livre circulação ou permanência em locais públicos.

Nesse sentido, outra observação refere-se à escassez de depoimentos femininos que identificaram, em vários âmbitos das relações sociais, situações de discriminação, com ênfase entre aquelas auto-classificadas como negras/pretas. Uma pergunta parece óbvia. Por que os relatos de discriminação entre as mulheres foram menos frequentes? Uma pista para esta questão se encontra nas colocações de Bourdieu (1998) a respeito do habitus da dominação masculina. Essa via nos permite entender o caráter sistemático da naturalização das diferenças entre homens $e$ mulheres e os processos pelos quais essa naturalização é tomada como um ponto de referência para fundamentar as assimetrias de gênero. Isso significa que, a despeito das conquistas alavancadas pelo movimento feminista nas ultimas décadas, é possível pensar 
na força das convenções de gênero em termos de hierarquia $e$ prestígio que presidem as relações sociais.

Ao mesmo tempo, não convém interpretar o silêncio apenas como evidência da aceitação de um papel subordinado, mas como uma forma específica de lidar com certos fenômenos sociais, conforme o gênero. As mulheres reconheceram situações de preconceito no ambiente de trabalho e não se furtaram a reagir quando se viram confrontadas com ofensas verbais, levantando suspeitas de caráter moral. As moças, assim como os rapazes entrevistados, entendem que os comentários preconceituosos sobre o local de moradia repousavam sobre noções preexistentes que associam pobreza e criminalidade, que reafirmam as hierarquias sociais. Em suma, a violência simbólica das falas estereotipadas sobre origem social não foi ignorada pelas mulheres. Este cenário remete as interfaces entre as hierarquias de cor/raça, classe e gênero, particularmente no contexto brasileiro, no qual a marcação da cor, como um princípio de classificação social, é associada à condição social e de gênero. Isso não significa que a identificação do racismo fique sempre subsumida à condição econômica ou a identidade de gênero e que a cor não jogue um papel relevante na dinâmica das opressões, mas que a mesma adquire contornos específicos em função dos contextos sociais.

\section{Referências bibliográficas}

ADORNO, Sérgio. Violência e Racismo: discriminação no acesso à justiça penal. In: SCHWARCZ, Lilian Moritz. \& QUEIROZ, Renato da Silva. (orgs.) Raça e Diversidade. São Paulo, EDUSP, Estação Ciência, 1996, pp.255-275.

BouRdiEU, Pierre. A dominação masculina. Rio de Janeiro, Bertrand Brasil, 1999.

Castro, Mary; Abramovay, Miriam; RUA, M.G.; Andrade, E. Cultivando vida, desarmando violências: experiências em educação, cultura, lazer, esporte e cidadania com jovens em situação de pobreza. Brasília, Organização das Nações Unidas para a Educação, a Ciência 
Cor, gênero e classe

e a Cultura/Brasil Telecom/Fundação Kellog/Banco Interamericano de Desenvolvimento, 2001.

CECCHETTO, Fátima. Violência e estilos de masculinidade. Rio de Janeiro, Editora FGV, 2004.

\& MONTEIRO, Simone. Discriminação, cor e intervenção Social entre jovens na cidade do Rio de Janeiro: a perspectiva masculina. Revista Estudos Feministas, 14(1), 2006, pp.199-218.

CRENSHAW, Kimberlé. Documento para o encontro de especialistas em aspectos da discriminação racial relativos ao gênero. Revista Estudos Feministas, vol. 10, n 1, 2002, pp.171-188.

CosTA, Sérgio. Formas e Dilemas do Anti-racismo no Brasil. In: SILVA, J.P. da; SANTOS, M.S. dos e RODRIGUES, I.J. (orgs.) Crítica Contemporânea: Cultura, Trabalho, Racismo e Política. São Paulo, Editora Annablume, 2002, pp.105-127.

DA MATTA, Roberto. A casa e a rua. São Paulo, Brasiliense, 1985.

FARIAS, Patrícia. Pegando uma cor na Praia: Relações Raciais e Classificação de cor na cidade do Rio de Janeiro. Rio de Janeiro, Secretaria Municipal das Culturas, Depto Geral de Documentação e Informação Cultural, Divisão de Editoração, Coleção Biblioteca Carioca, vol. 46, 2003.

FRY, Peter. Politicamente correto num lugar, incorreto noutro? Relações raciais no Brasil, nos Estados Unidos, em Moçambique e no Zimbábue. Estudos Afro-Asiáticos (21), dezembro de 1991, pp.167177.

- A Persistência da Raça: Ensaios Antropológicos sobre o Brasil e a África Austral. Rio de Janeiro, Civilização Brasileira, 2005.

. Ciência Social e política "racial" no Brasil. Revista USP Racismo1, n 68, São Paulo, dezembro/fevereiro, 2006, pp.180-187.

GuimarãEs, Antônio Sérgio. Cor, Classes e Status nos Estudos de Pierson, Azevedo e Harris na Bahia: 1940-1960. In: MAIO, Marcos Chor; SANTOS, Ricardo Ventura. (org.) Raça, ciência e sociedade. Rio de Janeiro, Fiocruz, 1996, pp.143-157.

. Preconceito e Discriminação. São Paulo. Editora 34, 2004.

GuIMARÃES, Nádia A. Gênero e Trabalho. Revista Estudos Feministas, vol.12, n 2, 2004. 
GRIN, Mônica. A celebração oficial da nova diversidade no Brasil. Revista USP - Racismo1, nº 68, São Paulo, dez/fev, 2006, pp.36-45.

HASENBALG, Carlos. Discriminação e Desigualdades Raciais no Brasil. Rio de Janeiro, Graal, 1979.

. Entre o Mito e os Fatos: Racismo e Relações Raciais no Brasil. In: MAIO, Marcos Chor; SANTOS, Ricardo Ventura. (org.) Raça, ciência e sociedade. Rio de Janeiro, Fiocruz, 1996, pp.235-249.

HEILBORN, Maria Luíza. Gênero e hierarquia: a costela de adão revisitada. Revista Estudos Feministas, vol. 1, nº 1, 1993.

HTUN, Mala. From "racial democracy" to affirmative action: changing state policy on race in Brazil. Latin American Research Review 39(1), 2004, pp.60-89.

LIMA, Márcia. Trajetória educacional e relalização sócio-econômica das mulheres negras. In: HASENBALG, Carlos; VALLE SILVA, Nelson e LIMA, Márcia. (orgs.) Cor e estratificação social. Rio de Janeiro, Contracapa Livraria, 1999, pp.148-158.

MAGGIE, Yvonne. Aqueles a quem foi negada a luz do dia: as categorias de cor e raça na cultura brasileira. In: MAIO, Marcos Chor; SANTOS, Ricardo Ventura. (orgs.) Raça, ciência e sociedade. Rio de Janeiro, Fiocruz, 1996, pp.225-234.

MAIO, Marcos, S. \& MONTEIRO, Simone. Tempo de Racialização: o caso da saúde da "população negra" no Brasil. História, Ciências, Saúde Manguinhos, vol. 12, n 2, maio-ago 2005, pp.419-446.

MAURício, Adriano. Medo de assalto. Dissertação de mestrado, Programa de Pos Graduação do IFCS da Universidade Federal do Rio de Janeiro, 1998.

MONTEIRO, Simone; CECCHETTO, Fátima. Trajetórias Juvenis e Intervenções Sociais: Repercussões nas Praticas Sociais e em Saúde (RJ, Brasil). Cadernos Saúde Pública 22 (1), jan 2006, pp.193-200.

MONTEIRO, Simone. Qual prevenção? Aids, sexualidade e gênero em uma favela carioca. Rio de Janeiro, Editora Fiocruz, 2002.

MOUTINHO, Laura. Razão, 'cor' e Desejo: uma análise comparativa sobre relacionamentos afetivo-sexuais 'inter-raciais' no Brasil e na África do Sul. São Paulo, Unesp, 2004. 
Cor, gênero e classe

NogueIRA, Oracy. Preconceito de Marca: As Relações Raciais em Itapetininga. São Paulo, Editora da Universidade de São Paulo, 1998.

PINTO, Elizabeth Aparecida; Souzas, Raquel. Etnicidade e saúde da população negra no Brasil. Cadernos de Saúde Pública, vol. 18, n 5 , 2002, pp.1144-5.

PINTO, Gabriel. Ação afirmativa, fronteiras raciais e identidades acadêmicas: uma etnografia das cotas para negros na UERJ. Trabalho apresentado na $1^{a}$ Conferência Internacional da Rede de Estudos de Ação Afirmativa, Rio de Janeiro, UCAM, janeiro de 2005. http://aasn.iuperj.br/Articles Paulo-Gabriel-Hilu.pdf, acessado em 7.6.2005.

RAMOS, Sílvia e MUSUMECI, Leonarda. (orgs.) Elemento suspeito: abordagem policial e discriminação no Rio de Janeiro. Rio de Janeiro, Civilização Brasileira, 2005.

PENA, Sérgio. Razões para banir o conceito de raça da medicina brasileira. História, Ciências, Saúde - Manguinhos, 12(2), 2005, pp.321-346.

SANSONE, Lívio. Negritude sem etnicidade: o local e o global nas relações raciais e na produção cultural negra do Brasil. Salvador, EDUFBA/Pallas, 2004.

SCHWARCZ, Lílian Moritz. As teorias raciais, uma construção histórica de finais do século XIX. O contexto brasileiro. In: Schwarcz, L. M. \& Queiroz, Renato da Silva. (orgs.) Raça e Diversidade. São Paulo, EDUSP/Estação Ciência, 1996, pp.147-185.

STOLKE, Verena. Sexo está para gênero assim como raça para etnicidade?. Estudos Afro-asiáticos (20), junho de 1991, pp.101-119.

TEIXEIRA, Moema De Poli. Negros na Universidade: identidade $e$ trajetória de ascensão social no Rio de Janeiro. Rio de Janeiro, Pallas, 2003.

TURRA, Cleusa; Venturi, Gustavo. (orgs.) Racismo cordial: a mais completa análise sobre o preconceito de cor no Brasil. São Paulo, Ática, 1995.

ZaluAR, Alba. Integração Perversa: pobreza e tráfico de drogas. Rio de Janeiro, Editora FGV, 2004. 
Fátima Cecchetto e Simone Monteiro

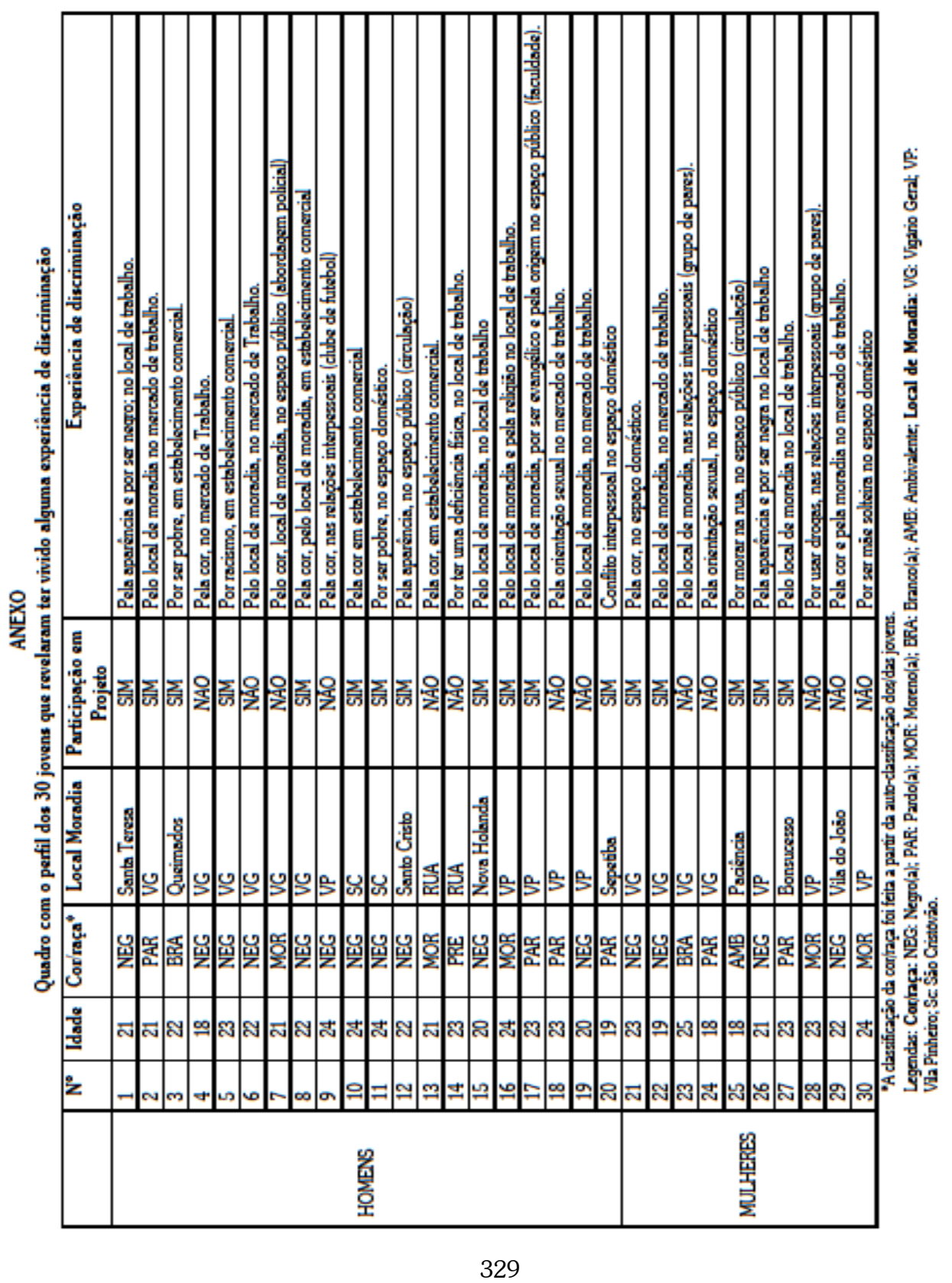

